\title{
Reduksi Resiko dan Peningkatan Efisiensi Kerja Kelompok Nelayan Sampan Layar di Desa Alasrejo Kecamatan Wongsorejo Kabupaten Banyuwangi
}

\author{
Gatut Rubiono ${ }^{1}$, Bayu Septa Martaviano ${ }^{2}$ \\ ${ }^{1}$ Program Studi Teknik Mesin, Universitas PGRI Banyuwangi \\ ${ }^{2}$ Program Studi Pendidikan Jasmani Kesehatan dan Rekreasi, Universitas PGRI Banyuwangi \\ Jl. Ikan Tongkol No. 01 Kertosari - Banyuwangi - Jatim 68416
}

Email: g.rubiono@unibabwi.ac.id

\begin{abstract}
Abstrak -. Nelayan di lingkungan Pesisir dusun Kebunrejo desa Alasrejo kecamatan Wongsorejo kabupaten Banyuwangi merupakan nelayan tradisional. Perahu yang digunakan adalah sampan kecil dengan layar. Penangkapan ikan dilakukan dengan pancing yang diulur dengan senar. Penyimpanan hasil tangkapan menggunakan kotak busa sederhana. Penggunaan layar memiliki permasalahan cuaca yang menyebabkan waktu tempuh perjalanan menangkap ikan keseluruhan sebesar \pm 5 jam. Besarnya waktu tempuh dan kotak penyimpanan sederhana menyebabkan kesegaran ikan tidak maksimal dan nilai jualnya relatif rendah. Kegiatan Program Kemitraan Masyarakat dilakukan dengan tujuan meningkatkan tingkat penghasilan nelayan dengan aplikasi mesin diesel berbaling-baling. Mitra berjumlah 4 (empat) orang nelayan. Kegiatan dilakukan dengan perancangan, pembuatan dan penggunaan mesin motor diesel 24 Hp dengan baling-baling 2 sudu berbahan kuningan sebagai pengganti tenaga penggerak layar. Hasil kegiatan menunjukkan bahwa mitra mendapatkan manfaat teknis meliputi perbaikan sarana penggerak perahu, peningkatan kecepatan gerak perahu di laut, kebutuhan dan biaya operasional bahan bakar yang relatif rendah, dan peluang pendapatan dari para pelaku wisata pemancingan ikan di laut.
\end{abstract}

Kata kunci: nelayan, tradisional, perahu, layar, mesin diesel

\begin{abstract}
Fishermen in the coastal area of Kebunrejo hamlet, Alasrejo village, Wongsorejo sub district, Banyuwangi district are traditional fishermen. The boat used is a small boat with a sail. Catching fish is carried out by fishing line which is stretched out with strings. Storage of catches using simple foam boxes. The use of sail has weather problems that cause the total fishing trip travel time to be \pm 5 hours. The amount of travel time and a simple storage box causes the freshness of the fish to be not optimal and the selling value is relatively low. Community partnership program activities are carried out with the aim of increasing the income level of fishermen with the application of diesel engines with propellers. The partners are 4 (four) fishermen. Activities carried out by designing, manufacturing and using a $24 \mathrm{Hp}$ diesel engine with 2 blades brass propeller as a replacement for the sail driving power. The results of the activity show that the partners get technical benefits including improvements to boat propulsion device, increased speed of movement of boats at sea, relatively low fuel needs and operating costs, and income opportunities from actors in sea fishing tourism.
\end{abstract}

Keywords: fishermen, traditional, boat, sail, diesel engine

\section{PENDAHULUAN}

Populasi jumlah nelayan di kabupaten Banyuwangi adalah 19.185 nelayan sambilan penuh dan 6.594 nelayan sambilan tambahan. Jumlah nelayan di Kecamatan Wongsorejo sebesar 1.061 nelayan sambilan penuh dan 361 nelayan sambilan tambahan [1]. Komunitas nelayan kecamatan Wongsorejo kabupaten Banyuwangi, khususnya desa Alasrejo dusun Kebunrejo lingkungan Pesisir mayoritas adalah nelayan tradisional yang menggantungkan perekonomian keluarga dari penjualan ikan hasil tangkapan.

Kecamatan Wongsorejo terletak di bagian timur sampai utara wilayah Banyuwangi. Nelayan tradisionalnya mencari ikan di daerah selat Bali dimana selat ini memiliki potensi seluas $960 \mathrm{mil}^{2}$ [1]. Selat Bali merupakan pertemuan Samudera Indonesia di sebelah selatan dan laut Jawa di bagian utara. Perbedaan ini menyebabkan adanya arus yang relatif kuat tetapi memiliki potensi ikan yang relatif besar. Di sisi lain, wilayah ini adalah lokasi penyeberangan Jawa Bali melalui jalur laut.

Modernisasi perikanan sudah berlangsung cukup lama di Indonesia, akan tetapi dalam realitas di lapangan memperlihatkan bahwa masyarakat nelayan yang berciri industrial belum sepenuhnya terwujud [2]. Keterbatasan teknologi di bidang kelautan merupakan masalah besar yang dimiliki setiap daerah pesisir di Indonesia. Partisipasi masyarakat merupakan faktor kunci keberhasilan 
proses pemanfaatan teknologi [3]. Penerapan alat bantu penangkapan ikan dapat mengurangi biaya operasional [4]. Kemampuan kelompok nelayan tradisional di bidang kemampuan teknologi ikan masih sangat rendah sehingga berdampak pada pendapatan yang tidak maksimal [5].

Nelayan merupakan salah satu subyek pembangunan pemerintah dalam ranah kelautan dan perikanan. Keadaan yang tidak menguntungkan membuat banyak perhatian pada nasib nelayan [6]. Cara penangkapan yang masih tergolong tradisional, pendidikan yang rendah dan sistem rantai penjualan hasil tangkapan ikan yang terlalu panjang merupakan faktor penyebab kondisi ekonomi nelayan Indonesia masih jauh dari tingkat sejahtera [7].

Berbagai kegiatan pengabdian kepada masyarakat telah dilakukan antara lain pelatihan dan pendampingan 19 orang nelayan besar (perahu ukuran di atas 5 GT) dan 58 orang nelayan kecil (perahu ukuran 2-5 GT) [6], pemberian bantuan kapal kayu bermotor 27 HP [7], pelatihan penentuan dan pemetaan daerah penangkapan ikan dengan GPS Map 585 dan alat deteksi kedalaman Side Scan Sonar [3], pelatihan perhitungan penggunaan es untuk pengawetan dan pemberian alat pendeteksi ikan fish finder [4], pemberdayaan melalui pelatihan pengawetan ikan dengan mesin pendingin [5], dan pemberdayaan kelompok nelayan melalui pengolahan hasil laut [8], tapi belum menyentuh kelompok nelayan berperahu sampan.

Nelayan di lingkungan Pesisir Kecamatan Wongsorejo menggunakan sampan (perahu kecil) yang masih menggunakan layar. Penangkapan ikan dilakukan dengan cara memancing menggunakan gulungan senar sehingga relatif ramah lingkungan. Penggunaan layar sangat tidak efektif karena membutuhkan waktu yang relatif lama untuk mengarungi jarak saat melaut ke lokasi penangkapan ikan yaitu 2,5 jam, tergantung pada cuaca. Hal ini menyebabkan pendapatan sehari-hari rata-rata antara $\mathrm{Rp} 50.000$,- sampai $\mathrm{Rp} 75.000,-$.

Perahu sampan umumnya berbahan kayu dan rata-rata memiliki ukuran panjang 5,5 - 10 meter, lebar 50 - $75 \mathrm{~cm}$ dan tinggi $70-100 \mathrm{~cm}$. Penyeimbang samping (cadik) umumnya digunakan bambu atau pipa PVC berdiameter 4 inchi. Bagian bawah geladak digunakan sebagai ruang penyimpanan peralatan, bekal dan hasil tangkapan. Hasil tangkapan ikan disimpan dalam kotak busa (box) yang diberi es secukupnya. Jarak tempuh dari lokasi penangkapan ikan ke pantai di pemukiman juga ditempuh minimal 2,5 jam. Penjualan dilakukan pada pengepul atau tengkulak yang menunggu di pantai dekat pemukiman atau rumah nelayan. Waktu tempuh yang relatif lama menyebabkan ikan hasil tangkapan relatif kurang segar sehingga harga jual relatif rendah.

Kendala waktu tempuh menyebabkan nelayan harus berangkat pagi sekali dan seringkali pulang saat senja bahkan malam hari. Kendala terberat adalah tidak adanya angin saat akan pulang yang menyebabkan nelayan harus mendayung ke daratan terdekat, karena perahu dapat terbawa arus yang mengalir dari Samudera Indonesia ke arah utara. Beberapa kali para nelayan harus mendaratkan perahunya di wilayah Bali (seberang Banyuwangi) untuk keselamatannya dan hasil tangkapan dijual sekedarnya. Saat musim kemarau, angin relatif kencang. Saat musim hujan, cuaca buruk dan gelombang laut menjadi kendala utama. Kelelahan fisik para nelayan karena waktu tempuh keseluruhan aktivitas menyebabkan mereka tidak dapat melakukan aktivitas setiap hari. Para nelayan hanya melaut dua hari sekali sehingga dalam waktu sebulan, rata-rata melakukan aktivitas menangkap ikan sebanyak 15 kali. Hal ini juga menyebabkan tingkat pendapatan per bulan yang relatif rendah.

Ketika sampan tidak digunakan maka layar digulung pada tiang. Saat berlayar, tiang penggulung ditegakkan agar dapat menangkap angin. Saat angin berhembus terlalu kencang maka para nelayan tidak berani menegakkan layarnya karena dorongan angin yang terlalu kuat dapat mengakibatkan perahu menjadi terbalik. Keterbatasan penghasilan bahkan memaksa para nelayan untuk mencari ikan pada kondisi angin yang tidak mendukung. Musim hujan juga menjadi penghambat bagi aktivitas mereka. Penggunaan mesin motor dengan baling-baling akan menyelesaikan banyak permasalahan para nelayan, dimana waktu tempuh diprediksi menjadi 30 menit.

Calon mitra kegiatan PKM ini adalah salah satu komunitas nelayan sampan di lingkungan Pesisir yaitu kelompok kecil beranggotakan 4 orang yang diketuai Bp. Sudai. Kelompok ini adalah para nelayan yang sering bekerja sama saat mencari ikan karena tingkat resiko yang telah diuraikan. Masingmasing anggota memiliki sampan sendiri atau bersama rekannya. Saat mencari ikan maka minimum 2 perahu nelayan akan berangkat bersama agar dapat saling membantu jika terjadi suatu permasalahan saat bekerja.

Dari paparan itu tampak bahwa aplikasi teknologi, khususnya teknologi tepat guna dapat digunakan dalam peningkatan kapasitas nelayan. Salah satunya dapat dilakukan dengan aplikasi mesin motor berukuran relatif kecil yang dilengkapi dengan baling-baling sebagai pengganti layar pada perahu (sampan) nelayan. 


\section{METODE}

Penguruan tinggi pengusul berada di pusat kota Banyuwangi. Mitra PKM berada di lingkungan Pesisir dusun Kebunrejo desa Alasrejo kecamatan Wongsorejo. Kedua lokasi dihubungkan dengan jalan propimsi dengan jarak $\pm 45 \mathrm{~km}$ dengan waktu tempuh $\pm 45-60$ menit.

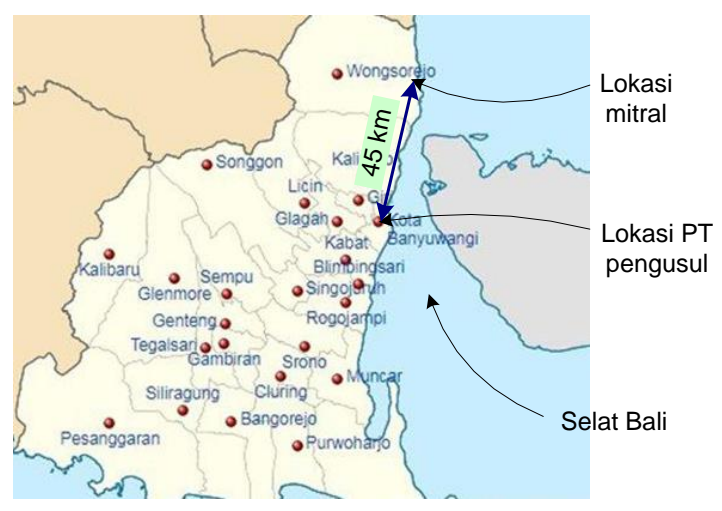

Gambar 1. Peta lokasi PT pengusul dan mitra

Kegiatan pengabdian masyarakat ini dilakukan dengan tahapan sebagai berikut:

1. Perancangan mesin perahu dan baling-baling.

Perancangan didasarkan pada hasil penelitian sesuai dengan referensi [9] dimana jumlah sudu baling-baling adalah 2 buah dengan sudut kemiringan poros sebesar $15^{\circ}$. Perancangan daya mesin dilakukan dengan survei pada nelayan lain di daerah sekitar yang telah menggunakan perangkat yang sama yaitu mesin diesel. Survei awal menunjukkan bahwa daya motor yang optimal adalah motor diesel 12-24 HP. Motor dengan daya yang lebih besar berarti ukuran dan berat juga lebih besar sehingga menjadi kendala pemasangan dan beban bagi perahu. Mesin dilengkapi dengan sistem transmisi sebagai pemindah daya.

2. Pembuatan baling-baling dan poros.

Poros menggunakan pipa baja diameter 2 inchi dengan panjang 2 meter. Sedangkan balingbaling dipilih berbahan kuningan.

3. Pemasangan mesin dan baling-baling.

Sebelum pemasangan dilakukan pengukuran buritan perahu dan perancangan landasan mesin. Hal ini dilakukan agar pemasangan sesuai dengan kondisi perahu dan menyesuaikan dengan posisi kemudi dan posisi kerja nelayan di perahu untuk memudahkan pengendalian. Mesin dipasang di bagian bawah perahu dengan dudukan khusus dan diposisikan di tengahtengah perahu untuk keseimbangan.

4. Uji coba perahu.

Dilakukan setelah mesin dipasang di perahu dan dilakukan pengukuran kecepatannya.

\section{HASIL DAN PEMBAHASAN}

Pada saat pelaksanaan, terjadi perubahan teknis dimana saat perencanaan program, dimana mitra memiliki perahu berukuran kecil (panjang 5 meter) untuk kapasitas maksimum 2 orang. Perahu ini memiliki kelemahan terhadap kestabilan terhadap ombak dan daya jelajah. Perahu-perahu kecil ini dirubah menjadi satu perahu besar berukuran panjang 9,5 meter dan lebar $80 \mathrm{~cm}$. Perahu jenis ini lebih stabil tetapi memerlukan tenaga penggerak yang lebih besar.

Perahu kecil yang menggunakan layar memiliki kecepatan 1-3 kilometer per jam. Hal ini dapat diukur menggunakan aplikasi pengukuran dengan HP Android. Perahu umumnya menggunakan mesin bensin bertenaga 5,5 HP. Bahan bakar bensin relatif mahal. Tenaga 5,5 HP memiliki kelemahan saat perahu harus bergerak melawan arus laut. Daya jelajah relatif kecil (1-2 kilometer dari garis pantai). Tenaga yang relatif kecil dapat membuat mesin menjadi kelelahan, panas dan dapat menimbulkan kerusakan saat dioperasikan. Perahu besar menggunakan mesin diesel, umumnya yang digunakan adalah mesin dengan tenaga minimum 8 HP untuk perahu dengan panjang 9 meter.

Mesin serbaguna sebagai mesin penggerak kapal banyak digunakan karena harganya yang terjangkau, mudah dalam perawatannya dan mudah dalam perolehan spare part pada saat dibutuhkan untuk perbaikan mesin [10]. Mesin diesel konstruksinya lebih sederhana dan biaya operasional lebih rendah, sehingga pemakaian mesin diesel lebih banyak disukai dari pada mesin uap atau mesin listrik [11]. Prinsip kerja motor diesel menggerakkan baling-baling melalui kopling dan poros baling-baling, sehingga baling-baling berputar menghasilkan gaya dorong maju atau mundur [12].

Bahan bakar diesel relatif lebih murah. Daya jelajah perahu akan meningkat sehingga dapat mencapai titik penangkapan ikan yang jauh lebih potensial. Perubahan ini telah disesuaikan dari segi teknis, meliputi:

a. Mesin diesel $24 \mathrm{HP}$.

b. Baling-baling berbahan kuningan yang tahan karat.

c. Kopling sebagai komponen pemindah tenaga.

d. Poros berdiameter $1 / 2$ inchi berbahan baja tahan karat.

e. Bahan-bahan kayu sebagai bahan pembantu.

f. Bahan-bahan besi sebagai rangka dudukan mesin.

g. Bahan untuk perbaikan cadik yaitu bambu dan pipa PVC untuk pelapis bambu.

h. Bahan-bahan pelengkap seperti cat, pelapis anti karat, mur baut, dan lain-lain 


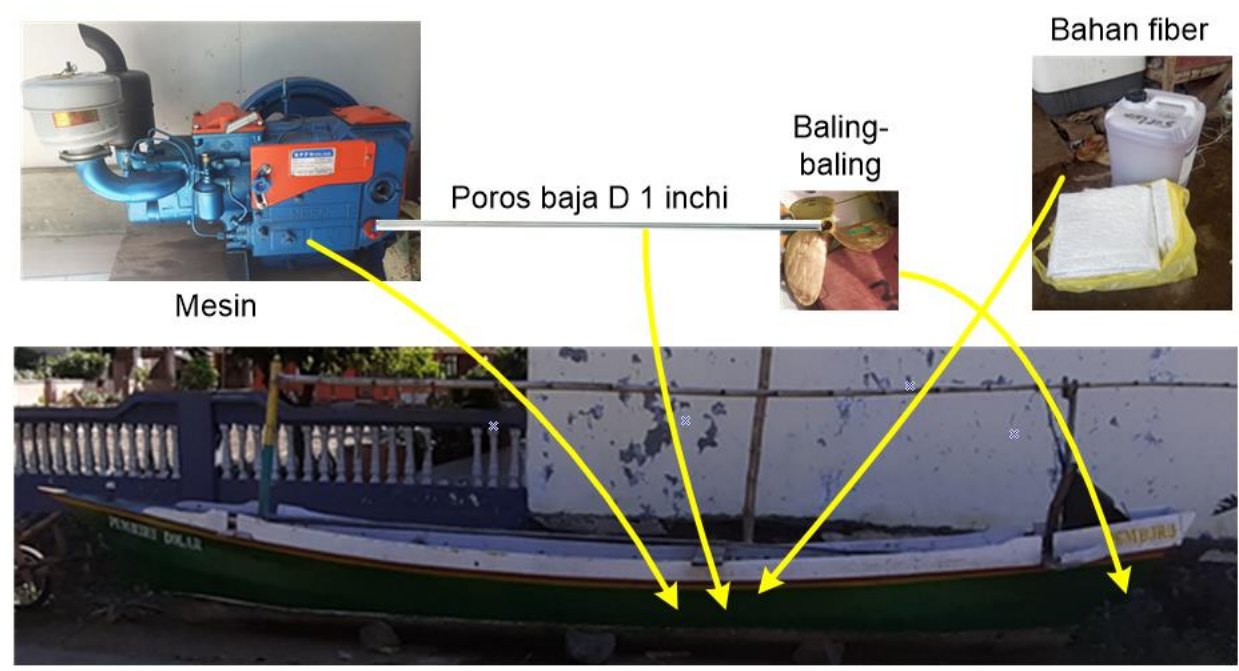

Gambar 2. Desain teknis pemasangan mesin dan baling-baling perahu

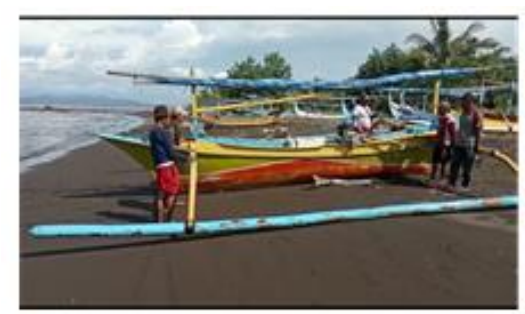

1. Survei lokasi

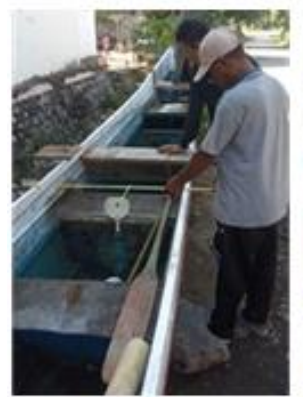

4. Pengukuran dimensi perahu

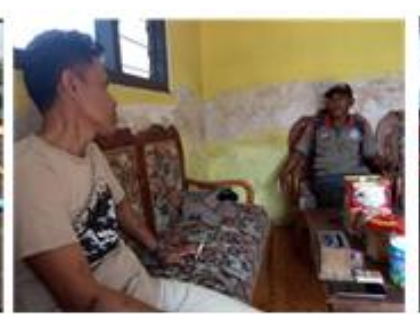

2. Diskusi teknis

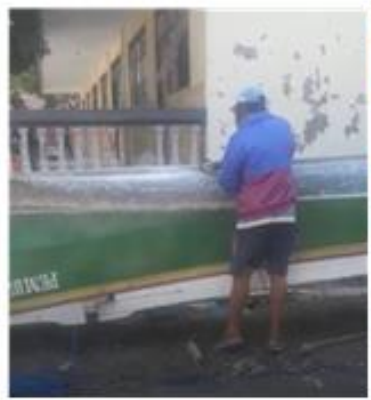

5. Pengerjaan penyesuaian badan perahu

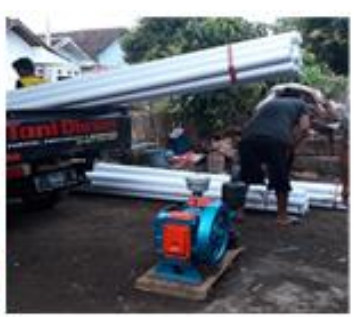

3. Belanja mesin dan bahan

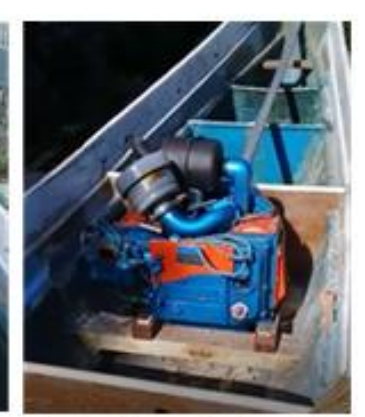

6. Posisi mesin di perahu

Gambar 3. Rangkaian kegiatan

Pengerjaan pemasangan mesin diesel dilakukan oleh tenaga yang telah dikenal di daerah sekitar mitra sebagai ahli pemasangan mesin perahu. Hal ini menuntut keahlian khusus karena perilaku perahu sangat berbeda dengan kendaraan darat. Pemasangan mesin perahu berbeda dengan kendaraan darat. Hal ini terkait dengan beban karena berat mesin dan keseimbangan perahu karena keseimbangan perahu merupakan faktor utama yang berhubungan dengan keselamatan. Permukaan air laut yang berombak dan berarus membutuhkan perahu yang stabil agar dapat terhindar dari kecelakaan.
Kecepatan gerak perahu di laut dapat diukur menggunakan aplikasi perangkat android untuk pengukuran kecepatan yang ada di handphone. Hasil pengukuran kecepatan perahu layar rata-rata sebesar 5 kilometer per jam. Hasil uji coba pemasangan mesin diesel di perahu dapat menghasilkan kecepatan rata-rata 10 - 15 kilometer per jam. Selain itu, 1 liter bahan bakar solar diperkirakan dapat digunakan untuk jarak tempuh 7,5 - 10 kilometer. Hal ini menunjukkan bahwa peningkatan kecepatan perahu relatif signifikan. Sedangkan dari segi operasional, kebutuhan dan biaya bahan bakar relatif rendah. 
Selain itu, manfaat lain yang diperoleh mitra dalam kegiatan ini adalah:

1. Secara teknis, perangkat penangkapan ikan menjadi jauh lebih baik. Daya jelajah perahu dapat menjangkau titik-titik penangkapan ikan yang relatif lebih jauh dan berpotensi untuk ikan-ikan yang berukuran relatif besar seperti tongkol, barakuda dan lain-lain.

2. Perubahan ukuran perahu memungkinkan bagi mitra untuk memberikan jasa bagi para pemancing rekreasi dimana perahu berukuran 9 meter memiliki kapasitas 7-9 orang. Hal ini merupakan potensi pendapatan alternatif bagi mitra. Informasi umum yang didapat, jasa pengantaran pemancing rekreasi di titik-titik pemancingan adalah Rp. 100.000 per orang.

\section{PENUTUP}

Kegiatan pengabdian mayarakat dengan mitra kelompok nelayan yang difokuskan pada pemberian mesin diesel sebagai tenaga penggerak menggantikan perangkat layar dapat memberikan manfaat dari aspek teknis berupa perbaikan perahu penangkapan ikan, peningkatan kecepatan gerak perahu, daya jelajah, dan peluang pendapatan selain aktivitas penangkapan ikan.

\section{UCAPAN TERIMAKASIH}

Kegiatan ini merupakan bagian Pengabdian Kepada Masyarakat yang didanai Ristek Dikti tahun anggaran 2020.

\section{DAFTAR PUSTAKA}

[1]. Dinas Kelautan dan Perikanan Kabupaten Banyuwangi, 2017, Selayang Pandang Perikanan Tangkap Kabupaten Banyuwangi.

[2]. A. Naim, 2011, Analisis Karakteristik Transformasi Industri Penangkapan Dalam Komunitas Masyarakat Nelayan (Studi Kasus Masyarakat Nelayan di Desa Panambuang Kab. Halmahera Selatan Provinsi Maluku Utara), Jurnal Ilmiah agribisnis dan Perikanan (agrikan UMMU-Ternate) 4(2): $23-37$
[3]. M. Z. Lubis, W. Anurogo, D. Pamungkas, 2018, Pemberdayaan Masyarakat Nongsa dengan Pembelajaran Penentuan Daerah Penangkapan Ikan Berbasis Teknologi di Bidang Kelautan, Jurnal Pengabdian Kepada Masyarakat - Indonesian Journal of Community Engagement 4(1): 11-18

[4]. A. A. Malik, 2018, Ipteks bagi Masyarakat (IbM) Kelompok Nelayan Purse Seine di Desa Siddo Kecamatan Soppengriaja Kabupaten Barru, Jati Emas (Jurnal Aplikasi Teknik dan Pengabdian Masyarakat) 2(2): 83-88

[5]. N. Suarnadwipa, I. W. B. Adnyana, H. Wijaksana, N. M. Suaniti, 2018, Pemberdayaan Masyarakat Nelayan Melalui Pelatihan Pengawetan Ikan Menggunakan Mesin Pendingin, Buletin Udayana Mengabdi 17(2): 106-110

[6]. R. Ma'arif, Zulkarnain, T. Nugroho, Sulistiono, 2016, Pemberdayaan Masyarakat Nelayan Melalui Pengembangan Perikanan Tangkap di Desa Majakerta, Indramayu, Jawa Barat, Agrokreatif, Jurnal Ilmiah Pengabdian Kepada Masyarakat 2(1): $17-24$

[7]. F. Ariani, I. Siregar, 2017, IbM Bantuan Perahu Motor Untuk Kelompok Nelayan Sejahtera di Desa Jaring Halus Kecamatan Sicanggang Untuk Meningkatkan Penghasilan dan Taraf Hidup Nelayan, Abdimas Talenta 2(2): 187-191

[8]. M. Kristiyanti, Siswadi, 2018, Pemberdayaan Kelompok Nelayan Desa Bandengan Jepara Melalui Pengolahan Hasil Laut, Praxis 1(1): 63-77

[9]. A. Munawir, G. Rubiono, H. Mujianto, 2017, Studi Prototipe Pengaruh Sudut Kemiringan Poros Baling-Baling Terhadap Daya Dorong Kapal Laut, V-Mac 2(1): 18-24

[10]. S. Sabiq, F. Purwangka, Y. Novita, 2018, Intensitas Kebisingan Mesin Serbaguna pada Perahu Gillnet di Pangkalan Pendaratan Ikan Pangandaran, Jurnal Ilmiah Samudra Akuatika 2(2): 9-21

[11]. F. Sarmento, I K. Suarsana, 2017, Pengaruh Pemanasan Awal Bahan Bakar Terhadap Unjuk Kerja Motor Diesel Dengan Bahan Bakar Solar dan Solar Dex, Jurnal Muara Sains, Teknologi, Kedokteran, dan Ilmu Kesehatan 1(1): 132-141

[12]. Dj. Andrijono, Sufiyanto, 2018, Bimtek Mutu Produk Cor Baling-Baling Kapal Nelayan Hasil Cetakan Pasir Dengan Bahan Dasar Skrap Aluminium Bagi IKM Disperindag Kota Pasuruan, Jurnal Abdimas Unmer Malang 3(2): 24-32 
Jati Emas (Jurnal Aplikasi Teknik dan Pengabdian Masyarakat)

Vol. 4 No. 2 Oktober 2020 - e. ISSN: 2550-0821 